\title{
Experimental research on chloride threshold level at low temperature: Part1 experiment procedure
}

\author{
Sijia Chen ${ }^{1, a}$, Xiaobing Song ${ }^{1, b}$ and Xila Liu ${ }^{1, c}$ \\ ${ }^{1}$ Shanghai Jiao Tong University, Shanghai 200240, China. \\ accj@163.com, bsongxb2014@163.com(corresponding author), cliuxila@sjtu.edu.cn
}

Keywords: Chloride threshold level, low temperature, steel corrosion, experimental research.

\begin{abstract}
Steel corrosion in concrete is a process of electrochemistry. When chloride content at the steel surface exceeds the chloride threshold level (CTL), the steel begins to corrosion. The CTL is one of the key parameters needed for service life prediction of concrete structures. Based on the electrochemistry theory, the CTL under $-20^{\circ} \mathrm{C}$ and room temperature are experimentally investigated. In this paper, the constant potential controlled and macrocell current measured to determine the corrosion initiation.
\end{abstract}

\section{Introduction}

Chloride threshold level(CTL) is one of the key parameters needed for service life prediction of concrete structures[1]. CTL depends on numerous factors[2], on which there are many research papers have been studied[3]. However, there are still some limitations of these researches. Most measurements of CTL were performed using a synthetic concrete solution[2], while only a few measurements were performed in mortar specimens[4]. Meanwhile, CTL at room temperature was more popular in research than at low temperature. However, assessment of the CTL at low temperature is a key element in predicting the service life of structures in cold regions exposed to chlorides.

In cold regions, the average air temperature can drop below minus twenty degree centigrade. At that temperature, synthetic concrete solution will be frozen, and CTL measurements can't be performed in the solution. However, the pore solution in concrete will not all be frozen. There are two main reasons. Firstly, the freezing point is lowed by the gradual increase in concentration of the ions dissolved in the part of the pore water that is not yet frozen. Secondly, the freezing point of pore solution also decreases with the diameter of the pores[5]. So, CTL at low temperature can be measured in concrete specimens.

Consequently, in this paper and the next paper (Part 2), based on electrochemical theory of steel corrosion, the CTL at low temperature $\left(-20^{\circ} \mathrm{C}\right)$ and room temperature are experimentally studied. With the results, the influence factors of CTL are discussed. Also, with the combination of other scholars' research, the relationship between $\mathrm{CTL}$ and temperature (from $-20{ }^{\circ} \mathrm{C}$ to $50{ }^{\circ} \mathrm{C}$ ) is researched.

\section{Experimental method and procedure}

Measurement of Corrosion Initiation. The onset of corrosion can be detected by monitoring the macrocell current between an anode and a cathode. Macrocell devices are widely used (ladder systems are common) to monitor the risk of reinforcement corrosion, with corrosion initiation shown by a sharp increase in the macrocell current. A macrocell consists of steel anodes and a single, nobler cathode usually made from titanium mesh, graphite or stainless steel; in practice, the whole macrocell is embedded in the concrete cover above the reinforcement[6]. In this paper, a macrocell consists of steel anode and stainless steel cathode. The results of preliminary test to measure the corrosion initiation are shown in Fig. 1. 

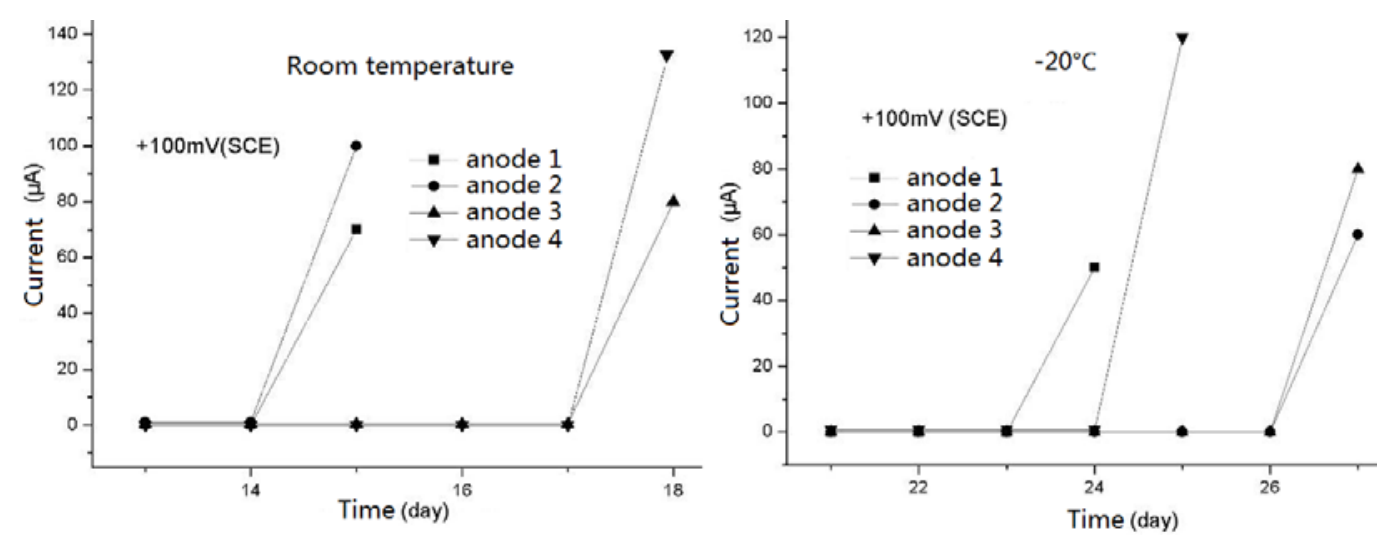

Fig. 1 Macro current changing of steel anodes at room temperature and $-20^{\circ} \mathrm{C}$ when potential is $+100 \mathrm{mV}(\mathrm{SCE})$

Steel Anode. According to the patent document[7], the steel anode is made as shown in Fig. 2. The work plane of a steel anode is polished by abrasive paper, and sealed with oil.

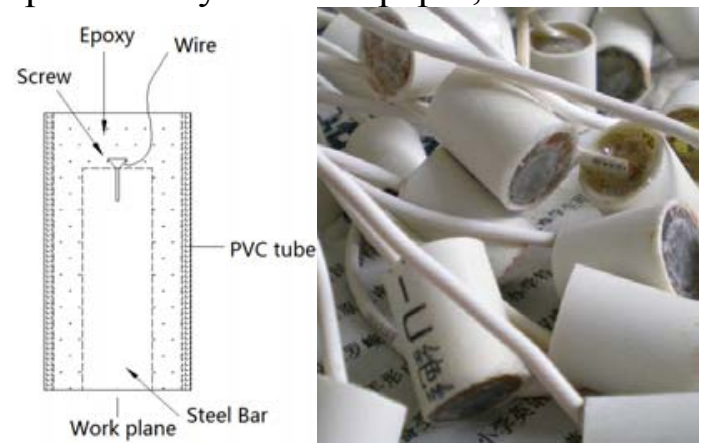

Fig. 2 Steel anodes

Specimens. Based on the size of steel anode, the concrete specimens' size are $40 \mathrm{~mm} \times 40 \mathrm{~mm} \times$ $40 \mathrm{~mm}$, as shown in Fig. 3. Four types of concrete were studied: three types of non-air-entrained concrete with water-cement (w/c) ratio of $0.47,0.59$ and 0.67 ; one type of air-entrained concrete and $\mathrm{w} / \mathrm{c}=0.47$. The mix proportions of concrete are show in Table 1 . Corrosion potential and temperature are considered in this experiment as influence factor. Totally, the number of specimens is 136 . As chloride penetration should be controlled only from one plane into a specimen, the other planes of the specimen should be sealed by paraffin, as shown in Fig. 3.

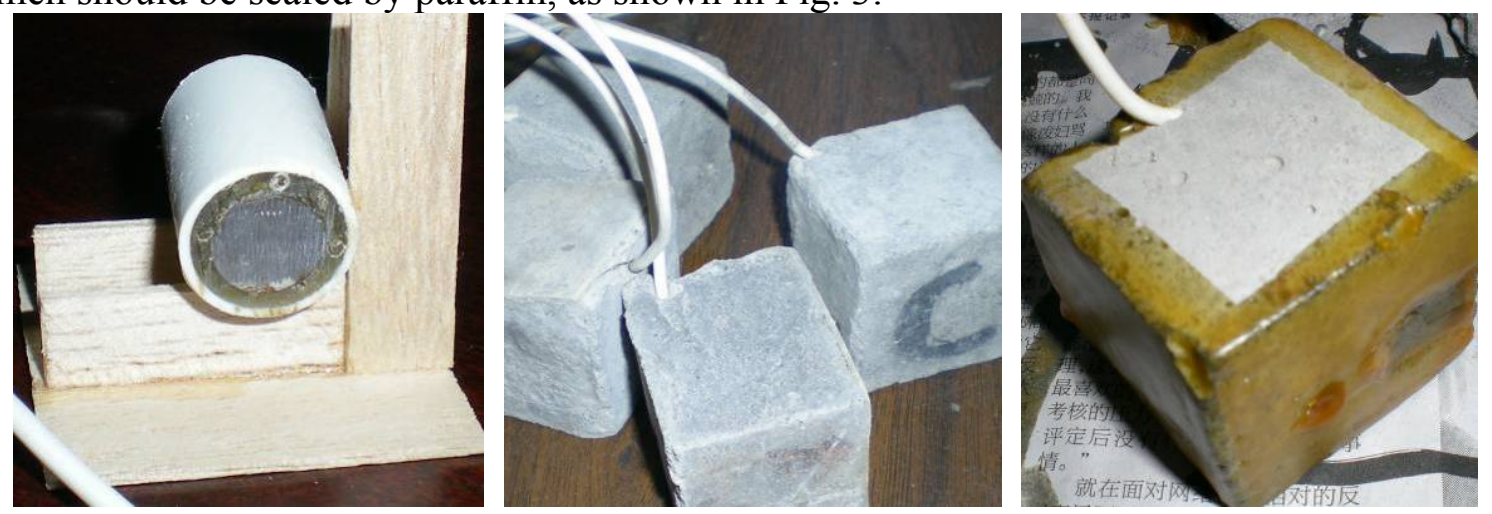

Fig. 3 Steel anode (left),casted specimens(middle) and Paraffin-coated specimen (right)

Table 1 Mix proportions and major parameters of concrete

\begin{tabular}{cccccc}
\hline Series & $\begin{array}{c}\text { Cement } \\
\left(\mathrm{kg} / \mathrm{m}^{3}\right)\end{array}$ & $\begin{array}{c}\text { Air-entraining } \\
\text { agent }\left(\mathrm{kg} / \mathrm{m}^{3}\right)\end{array}$ & $\begin{array}{c}\text { Water } \\
\left(\mathrm{kg} / \mathrm{m}^{3}\right)\end{array}$ & $\begin{array}{c}\text { Coarse } \\
\text { aggregate } \\
\left(\mathrm{kg} / \mathrm{m}^{3}\right)\end{array}$ & $\begin{array}{c}\text { Sand } \\
\left(\mathrm{kg} / \mathrm{m}^{3}\right)\end{array}$ \\
\hline A & 338 & 0 & 159 & 1000 & 874 \\
B & 320 & 0 & 189 & 1000 & 874 \\
C & 297 & 0 & 199 & 1000 & 874 \\
D & 338 & 1.01 & 159 & 1000 & 874 \\
\hline
\end{tabular}


Test system. In this paper, the Potentiostat PS-1 is used to control the different potential with SCE as the reference electrode, as shown in Fig. 4. Stainless steel slice $(100 \mathrm{~mm} 100 \mathrm{~mm} \times 1 \mathrm{~mm})$ is used as cathode. In this paper, $\mathrm{CaCl}_{2}$ was chosen to produce the salt solution to make chloride ingress into concrete. In order to prevent the $\mathrm{CaCl}_{2}$ solution to be frozen in the freeze-thaw cycles, the concentration of $\mathrm{CaCl}_{2}$ solution was chosen to be $29 \%$.

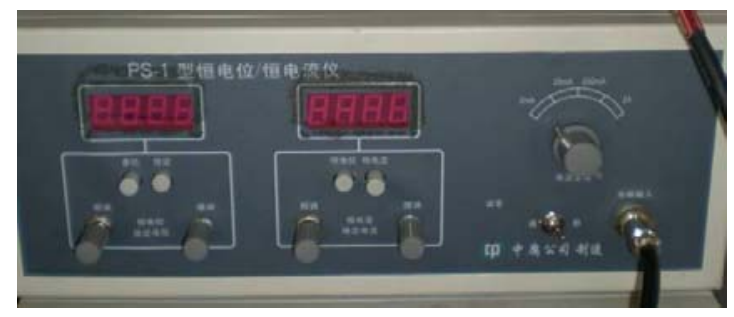

Fig. 4 Potentiostat PS-1

As the specimens are so many and they should be tested at the same time, the test system should be designed. This system should separate each steel anode apart, and it should insure that every anode can be connected to cathode when it would be tested. The different salt solution container should be connected by salt bridge. The ammeter should also in the system to get the electric current in each circuit for each anode at any time with different switches on and off. Consequently, the test system is designed as shown in Fig. 5, and the actual system is built as shown in Fig. 6.

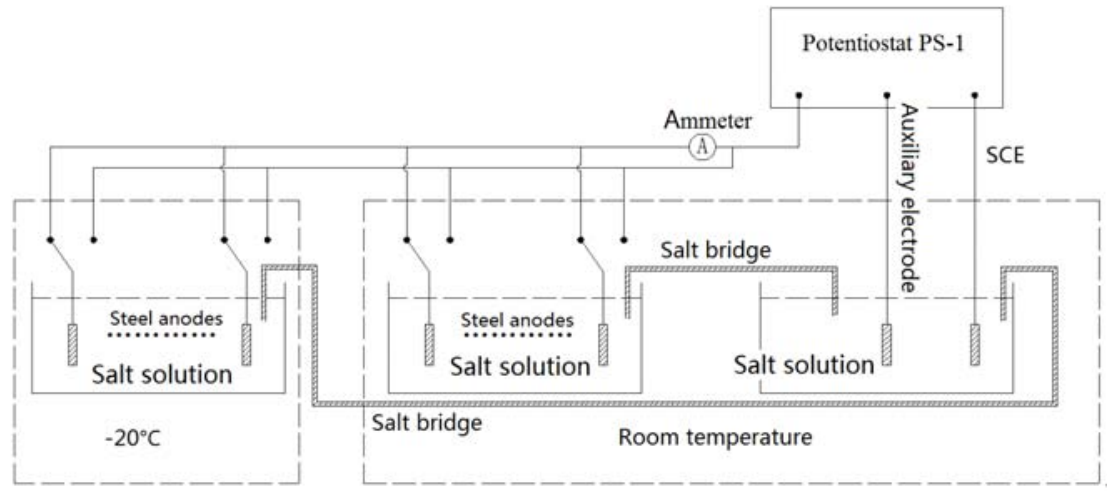

Fig. 5 Design of test system

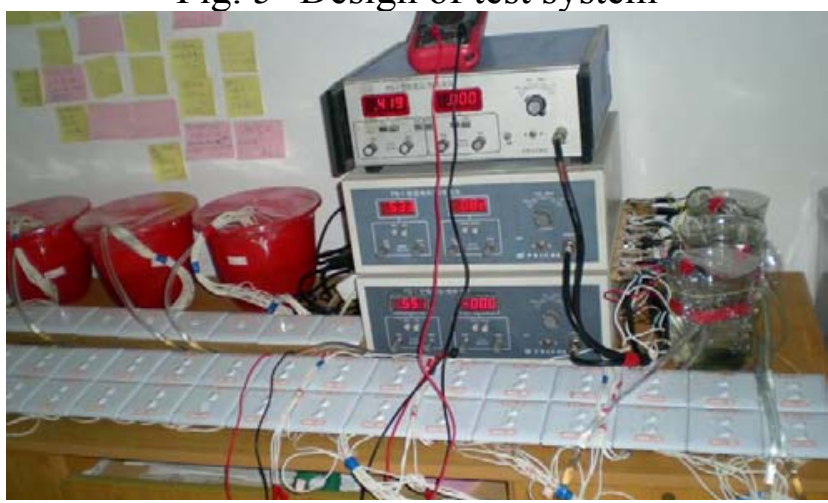

Fig. 6 Test system

Chloride concentration determination. When corrosion initiation in a specimen is measured, the specimen will be crushed to get some concrete samples (Fig. 7) near the anode work plane. The obtained concrete powder will be analyzed for chloride concentration by Chloride selective electrode system, as shown in Fig. 8. 


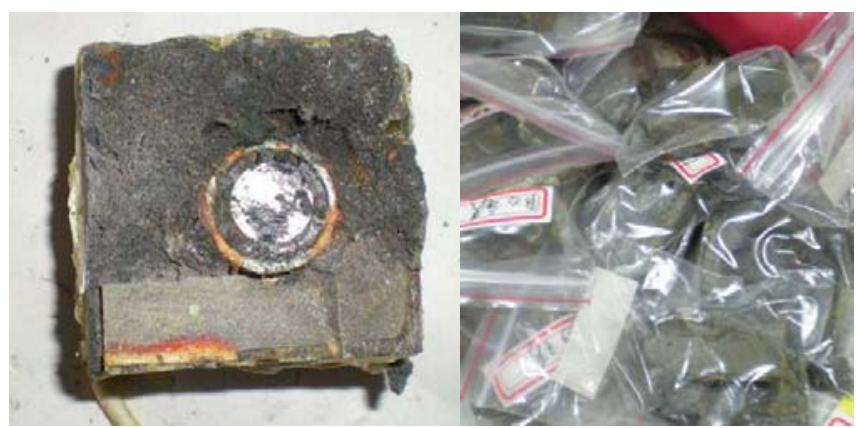

Fig. 7 Corrosion steel anode（left） and adjacent concrete samples（right）

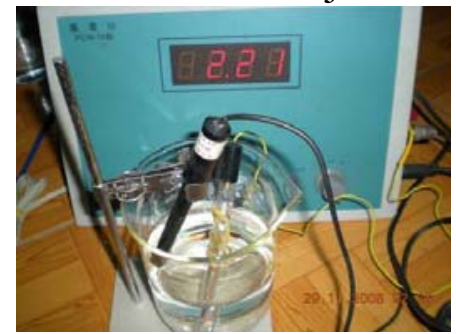

Fig. 8 Chloride selective electrode system

CTL representation. The representation of CTL reflects the aggressive ion content and inhibitive properties of the cement matrix. Early works suggested that only the free chloride contributes to the corrosion process. However, from recent decades' research, the total chloride, $\mathrm{Cl}^{-} / \mathrm{OH}^{-}$, and $\mathrm{Cl}^{-} / \mathrm{H}^{+}$are also can be the representations for CTL[8]. In this paper, the free chloride content is taken as the representations for CTL.

\section{Summary}

From all above, the CTL under low temperature and normal temperature are obtained. In next paper (Part 2), the results will be discussed from different aspect, and the influence factor on CTL also will be discussed.

\section{References}

[1] Shamsad Ahmad, Reinforcement corrosion in concrete structures, its monitoring and service life prediction--a review, Cem. Concr. Compos. 25(2003)459-471.

[2] C.Alonso, Chloride threshold dependence of pitting potential of reinforcements, Electrochim. Acta. 47(2002)3469-3481.

[3] C.Alonsoa, C.Andrade, M.Castellote, et al., Chloride threshold values to depassivate reinforcing bars embedded in a standardized OPC mortar, Cem. Concr. Res. 30(2000)1047-1055.

[4] Bolzoni F. Bertolini L., T. Pastore, Pedeferri P, Corrosion of Reinforcement in Concrete Construction, Cambridge: 1996.

[5] Bernhard Elsener Luca Bertolini, Pietro Pedeferri,Rob Polder, Corrosion of Steel in Concrete, WILEY-VCH, 2004.

[6] Ki Yong Ann, Ha-Won Song, Chloride threshold level for corrosion of steel in concrete, Corros. Sci. 49(2007)4113-4133.

[7] X. Song and X. Liu, Split adjustable sensor for monitoring reinforcement corrosion long-term, China, CN200810036154.0. (2008).

[8] B. Reddy G. K. Glass, N. R. Buenfeld, Corrosion inhibition in concrete in concrete arising from its acid neutralization capacity, Corros. Sci. 42(2000)1587-1598. 